\title{
Emotional Intelligence as a Predictor of Writing and Public Speaking Anxieties
}

\author{
Stephanie Kelly', Tiffany Smith², Wiley Brown \\ ${ }^{1}$ North Carolina A\&T State University, Greensboro, NC, USA \\ ${ }^{2}$ University of North Carolina at Greensboro, Greensboro, NC, USA
}

Objectives: Students and professionals who suffer from communication anxiety may have all of the skills necessary to be excellent communicators, but unable to communicate effectively as they struggle with that anxiety. Guided by the Instructional Beliefs Model, the purpose of this study is to evaluate emotional intelligence (EQ), a developable skill, as an indirect influence of writing and presentation anxieties.

Methods: An online survey was disseminated to 224 business majors. Each were assessed on the dimensions of EQ, self-efficacy, writing apprehension, and public speaking anxiety.

Results: The data supported a model in which the EQ dimensions of well-being and self-control, which are the dimensions of EQ that are oriented toward one's own emotions, indirectly influence students' public speaking anxiety through the mediation of self-efficacy. However, while all EQ dimensions were negatively correlated with writing apprehension, none appear to be an indirect influence of it.

Conclusions: The findings of this study indicate that elevating an individual's well-being and self-control can ultimately give them the tools they need to manage their anxiety when giving presentations. Through instructional strategies known to enhance these characteristics, business educators and organizational trainers should be able to assist individuals in giving better presentations.

Key Words: Communication Anxiety, Writing, Public Speaking, Emotional Intelligence (EQ), Self-Efficacy

\section{Introduction}

Communication skills are critical for students of all majors if they wish to be successful in their careers (Gaffney, 2013). Yet anxiety about a particular method of communication can pre-

Received: Dec 4, 2019 Revised: Dec 31, 2019 Accepted: Feb 21, 2020 Corresponding author: Stephanie E. Kelly North Carolina A\&T State University, Greensboro, NC, USA Tel: +1-336-285-4903, E-mail: sekelly@ncat.edu

This is an Open Access article distributed under the terms of the Creative Commons Attribution Non-Commercial License (http://creativecommons.org/licenses/ by-nc/4.0/) which permits unrestricted non-commercial use, distribution, and reproduction in any medium, provided the original work is properly cited.

Copyright $\odot 2020$ Korean Association for Business Communication. vent students and young professionals from demonstrating the competence they truly have in communication (Prentiss \& Violanti, 2019). Anxiety hinders performance through its impact on working memory (Kelly, Rice, Wyatt, Ducking, \& Denton, 2015). Working memory is the part of the human brain that processes in the moment information and functions. That means it is the same resource required to compose a message, solve a math problem, or manage anxiety symptoms (Miller \& Bichsel, 2004). Because of this, the more anxiety symptoms someone has, the more working memory must be devoted to managing its symptoms, leaving less working memory to perform a task. For this reason, if educators do not help students manage their communication anxieties, it can prevent them from performing 
well in the classroom and future careers.

Two contexts in which communication anxieties can be particularly detrimental for future and current professionals is writing apprehension and public speaking anxiety. Writing and making presentations are an inevitable and continuous part of professional careers (Bodie, 2010; Kelly \& Gaytan, 2020). Because of this, business educators must strive to help students manage these communication anxieties before they leave the classroom. While the majority of inoculation research has focused on learning activity, instructional communication, or therapeutic interventions for improving these anxieties (e.g., Kelly \& Gaytan, 2020; Lindner et al., 2019), this paper will examine pre-existing student characteristics that may be developed. Specifically, this paper will test a path model in which students' emotional intelligence (EQ) is expected to influence their communication anxieties through the mediation of self-efficacy.

\section{Literature Review}

\section{Emotional Intelligence}

EQ is one's ability to comprehend the emotions of others and oneself, control one's own emotions, and also strategically use that emotional acumen to influence others (Bar-On, 2006). Petrides et al. (2016) explains that EQ has four dimensions: well-being, self-control, emotionality, and sociability. Well-being is composed of one's self-confidence in their ability to manage their emotions and default to happy or optimistic attitudes. Self-control is one's ability to manage their own emotions, stress, and impulses. Emotionality is the ability to perceive the emotions of others and express or accept empathy. Lastly, sociability is the ability to perceive and adapt to the emotions of others.

Individuals who have higher EQ tend to have fewer social anxieties than those with low EQ (Abdollahi \& Abu Talib, 2016). Individuals with higher $E Q$ are also perceived to be more socially competent (Jordan \& Troth, 2011). When focusing on a task, high EQ gives one the ability to be more productive and successful because they can regulate their own emotions rather than becoming distracted by them (Serrat, 2017).

In the workplace, individuals who have strong EQ are perceived to be more effective communicators by their colleagues (Moon \& Hur, 2011). Workplace leaders, especially those who are successful in a global environment, tend to be more successful if they have higher EQ (Colfax, Rivera, \& Perez, 2010). These leaders are able to adapt their communication styles to the social needs of their subordinates, leading to increased job satisfaction for those subordinates (Matthew \& Gupta, 2015). Workers with high EQ also tend to have less anxiety about conducting business with colleagues of another culture (Fall,
Kelly, Macdonald, Primm, \& Holmes, 2013), which has become increasingly essential in today's global economy.

Though individuals are born with a natural baseline of EQ (Petrides et al., 2016), EQ is a skill that can be developed across a lifetime (Colfax et al., 2010). A variety of tested pedagogical activities have been introduced to increase students' EQ which involve assessment (Kelly \& Claus, 2015), simulations (Mabry, 2011), service learning (Cicilia, Musa, Walanda, Tangge, \& Jamhari, 2017), and EQ theory exposure (Myers \& Tucker, 2005).

\section{Self-Efficacy}

Self-efficacy is an individual's belief of how capable they are at planning and executing courses of action successfully (Artino, 2012). In Bandura's (1986) seminal writing on self-efficacy, he explains that educators' understanding student self-efficacy is critical because students will be reluctant to even attempt learning material in a subject in which they do not feel they have some efficacy. As such, without a baseline of self-efficacy in a subject, students will avoid learning and practicing skills related to the subject (Schunk, 2003).

Students' motivation and learning in the classroom are strongly predicted by their self-efficacy (Zimmerman, 2000). Students with higher self-efficacy are more likely to participate in class discussions and activities than students with low self-efficacy (Johnson \& Kelly, 2020). Further, student self-efficacy strongly predicts their academic resilience, that is, their willingness to continue attempting to learn even if they have found the task to be difficult (Cassidy, 2015). Students' self-efficacy also predicts how engaged they will be with their instructor (Linnenbrink \& Pintrich, 2003). LaBelle, Martin, and Weber (2013) found that students' self-efficacy was a direct influence of whether students engaged in rhetorical dissent, which is asking critical questions about assignments, course materials, and grading policies that students must understand to perform optimally.

In a study of business communication students, Autman and Kelly (2017) found a small negative correlation between students' self-efficacy and their writing apprehension. Mascle (2013) found that many business majors struggle to transfer their writing skills into a writing context, and while additional writing training was not useful in fixing their writing apprehension, enhancing their self-efficacy was useful.

\section{Communication Anxieties}

Anxiety about communication can be induced by the actual act of communicating or by simply anticipating that communication will happen (McCroskey, 1982). The symptoms of communication anxieties can be both physical and physiological, 
ranging from sweating palms and a racing heart to one's mind going blank (Prentiss \& Violanti, 2019). Communication anxieties can happen in any communication context, but are most frequently studied in public speaking, meeting, interpersonal and group contexts (Croucher et al., 2019). This study will focus on anxieties as they manifest in writing and public speaking.

\section{Writing Apprehension}

Writing apprehension, though it is traditionally called an apprehension rather than anxiety in the literature, is the communication anxiety specific to writing tasks (Autman \& Kelly, 2017). Writing apprehension is the angst some individuals feel when forced to write that results in lower motivation, confidence, and overall skill in writing (Daly \& Miller, 1975; Limpo, 2018). It is a situational form of communication apprehension induced by the need to transmit a message or record information whether the channel is pencil and paper or electronic (Prentiss \& Violanti, 2019).

For college students, writing apprehension is typically most pronounced when their writing is going to be assessed (Daly \& Miller, 1975). Many college students suffer from writing apprehension and as a result avoid writing training and assignments (Ahrens, Meyers, Irlbeck, Burris, \& Roach, 2016). Students are not apprehensive about writing because they are bad at writing though; rather, writing apprehension causes many students who are perfectly capable of being excellent writers to struggle to perform well as their apprehension becomes a barrier (Autman \& Kelly, 2017).

Instructors can inoculate students against writing apprehension while they are in the college classroom. High instructor clarity and nonverbal immediacy behaviors both lead to a reduction of student writing apprehension (Kelly \& Gaytan, 2020). Creating assignments that allow students to practice the entire writing process from conception, to writing, to editing, to reflecting also helps students manage their writing apprehension over the course of a semester (Fischer et al., 2017). Unfortunately, there is no evidence to indicate that these instructor inoculations for writing apprehension continue to help students once they leave the classroom and enter the workplace. Additionally, the nonverbal immediate behaviors studied in the face-to-face classroom can only be shared with online students in very rich communication channels (Kelly \& Gaytan, 2020). The online environment limits channel richness, leaving professors with one less tool for helping students manage their writing anxiety in the online environment, particularly in asynchronous courses.

\section{Public Speaking Anxiety}

Public speaking anxiety is a situational type of communication apprehension brought on by being forced to speak before an audience (McCroskey, 1982), more recently defined as anxiety one feels when giving a presentation (Prentis \& Violanti, 2019). Public speaking anxiety is the most common form of communication apprehension, with many people fearing public speaking more than death itself (Dwyer \& Davidson, 2012). Yet, presentations are an essential part of both university studies and professional careers (Bodie, 2010).

Like writing apprehension, public speaking anxiety can improve over time through practice (Bodie, 2010). However, the effects of public speaking anxiety can be even more detrimental on performance than writing apprehension because public speaking is assessed in the moment as speakers are struggling against the physiological symptoms of anxiety such as a racing heart, sweat, and/or shaking hands, whereas with writing individuals at least have the opportunity to edit for mistakes before their messages are evaluated. Many individuals experience public speaking anxiety just through thinking about an anticipated presentation, long before a presentation actually begins (Homer, Deeprose, \& Andrade, 2016; McCroskey, 1982).

Early efforts to address students' public speaking anxiety focused on repeated practice (Finn, Sawyer, \& Behnke, 2009). Today, the standard of immersion therapy in the form of continuous forced practice has not changed except that it has been expanded beyond live audiences to include virtual reality (Harris, Kemmerling, \& North, 2002). Students can also benefit from discussing their public speaking anxiety as they learn they are not alone and others are sympathetic rather than judgmental in regard to their anxiety (Bodie, 2010).

\section{Rationale}

Previous research has found positive relationships between global EQ scores and self-efficacy (e.g., Hen \& Goroshit, 2014; Salami, 2010). Consistent with the findings of such studies, this study expects to find positive relationships between EQ and self-efficacy, but will examine EQ in its individual subdimensions for a more nuanced understanding of EQ. Thus, the following hypotheses are proposed:

- Hypothesis 1: Emotionality will be positively correlated with self-efficacy.

- Hypothesis 2: Sociability will be positively correlated with self-efficacy.

- Hypothesis 3: Well-being will be positively correlated with self-efficacy.

- Hypothesis 4: Self-control will be positively correlated with self-efficacy.

Also consistent with previous literature (e.g., Autman \& Kelly, 2017; Lucchetti, Phipps, \& Behnke, 2003), it is expected that 
self-efficacy will be negatively related to communication anxieties. Specifically, the following hypotheses are proposed:

- Hypothesis 5: Self-efficacy will be negatively correlated with writing apprehension.

- Hypothesis 6: Self-efficacy will be negatively correlated with public speaking anxiety.

Although these relationships have been observed in previous literature (albeit the EQ relationships in a less nuanced way), it is not clear whether these relationships are spurious or relationships of influence.

The Instructional Beliefs Model (IBM) explains that student characteristics indirectly affect their learning outcomes, including anxieties, through the mediation of students' beliefs about their abilities (Weber, Martin, \& Myers, 2011). In other words, the IBM explains that student characteristics (e.g., EQ) directly influence their beliefs about their own abilities (e.g., self-efficacy), and that those beliefs about their abilities then in turn influence their learning outcomes (e.g., public speaking anxiety and writing apprehension). Therefore, it is predicted, in alignment with the IBM, that these six hypotheses form a path model in which students' EQ influences their self-efficacy, which in turn influences their communication anxieties. The proposed model is depicted in Figure 1.

\section{Method}

\section{Participants}

In total, 224 business majors participated in this study. The majors of participants broke down as follows: 27 accounting, 8 business analytics, 25 business education, 36 business information technology/systems, 26 economics, 6 finance, 23 market- ing, 51 management, and 22 supply chain. Rank broke down as follows: 34 freshmen, 40 sophomores, 68 juniors, 60 seniors, and 22 graduate students. There were 90 participants who identified as biologically male, 133 who identified as biologically female, and none who identified as other. The average age of the participants was $23.17(S D=6.18)$ years old.

\section{Procedure}

The researchers emailed personal contacts who they knew were teaching business courses during the fall 2019 semester and asked them to share a link to an online questionnaire with their students. This link directed students to an informed consent, which stated that completion of the questionnaire would require approximately 10 minutes and that no identifying information would be recorded. If participants chose to accept the informed consent, their browser was redirected to the questionnaire. This method of solicitation resulted in 144 participants. Qualtrics was then enlisted to share the link with 80 additional business majors.

\section{Instruments}

\section{Emotional Intelligence}

EQ was measured through Petrides and Furnham's (2006) Trait EQ Questionnaire-Short Form. This measure includes 30 items Likert-type with a 7-point response scale ranging from Disagree Strongly to Agree Strongly. Petrides and Furham (2006) report that this condensed measure yielded evidence of content validity.

\section{Self-Efficacy}

Autman and Kelly's (2017) self-efficacy measure was used, which was refined in a sample of business majors from

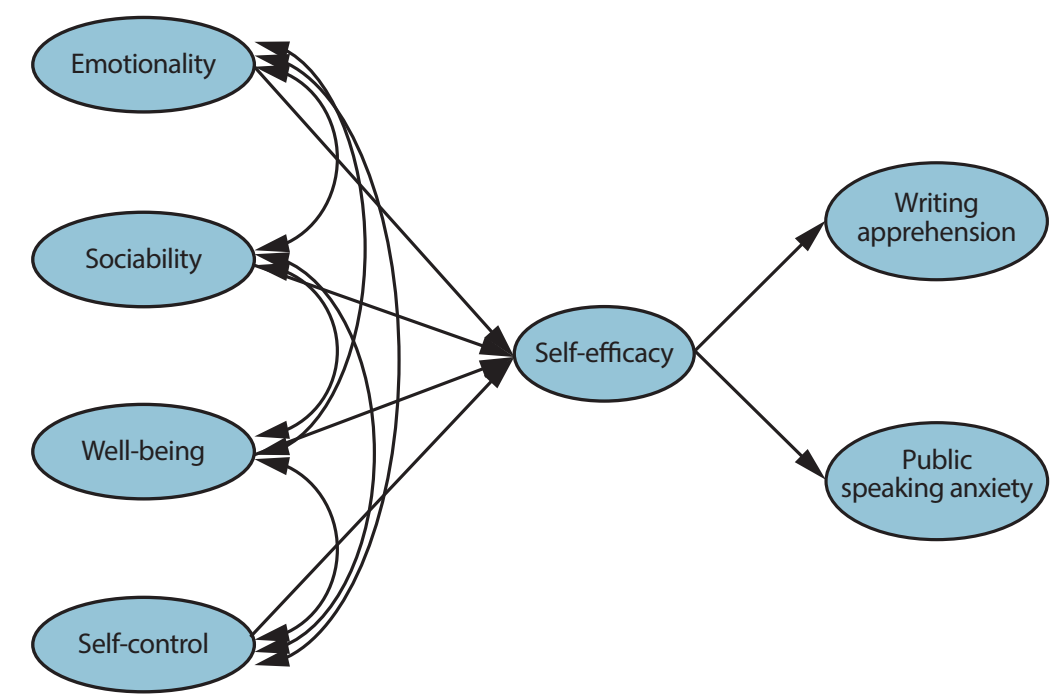

Figure 1. Proposed model. 
Schwarzer and Jerusalem's (1995) measure. It includes seven Likert-type items with a 7-point response scale ranging from Disagree Strongly to Agree Strongly. Autman and Kelly (2017) reported that the measure showed evidence of content and concurrent validity.

\section{Writing Apprehension}

Writing apprehension was assessed through Autman and Kelly's (2017) writing apprehension measure. This measure was constructed with a validity portfolio among business students. It is composed of seven Likert-type items with a 7-point response scale ranging from Disagree Strongly to Agree Strongly. The published validity portfolio showed evidence of content and concurrent validity (Autman \& Kelly, 2017).

\section{Public Speaking Anxiety}

Public Speaking Anxiety was measured through McCroskey's (1982) submeasure of the Personal Report of Communication Apprehension (PRCA). Croucher et al. (2019) recently cautioned scholars that the global fit of the PRCA no longer holds, but that submeasures, such as the public speaking anxiety submeasure, may still work among today's college students with respecification. The measure included six Likert-type items with a 7-point response scale ranging from Disagree Strongly to Agree Strongly.

\section{Results}

\section{Measurement Models}

Before testing any of the hypotheses, confirmatory factor analyses (CFA) were run on each of the measurement models to scrutinize for potentially problematic items that contribute to measure misfit. Items that caused a statistically significant amount of residual error on other items in the measure were removed. The self-efficacy and writing apprehension measures yielded no problematic items. Public speaking anxiety lost two items through the CFA process, as predicted by Croucher et al. (2019). The EQ submeasures each lost at least one item: well-be- ing lost one item, self-control lost two items, emotionality lost two items, and sociability lost two items. The fit statistics for the original and respecified measurement models can be seen in Table 1, and descriptive statistics for the final measures are listed in Table 2.

An overview of sample homogeneity then conducted. The mean scores for each variable are broken down by student major, sex, and rank in Table 3. One-way ANOVAs revealed no statistically significant difference between groups for emotionality $(F(8,215)=1.15, p=.33)$, self-control $(F(8,215)=1.26, p=$ $.27)$, well-being $(F(8,215)=0.77, p=.63)$, sociability $(F(8,215)$ $=.80, p=.61)$, self-efficacy $(F(8,215)=1.29, p=.25)$, or writing apprehension $(F(8,215)=1.75, p=.09)$. There was minor heterogeneity for public speaking anxiety as a statistically significant difference was found between only the 8 business analytics majors and 36 business information technology/information systems majors $(F(8,215)=2.45, p=.02)$. Independent t-tests revealed no statistically significant differences by gender for any

Table 1. Fit statistics of confirmatory factor analyses

\begin{tabular}{lllll}
\hline Variable & GFI & CFI & RMSEA & SRMR \\
\hline Original & & & & \\
Self-efficacy & 0.88 & 0.90 & 0.17 & 0.06 \\
Writing apprehension & 0.94 & 0.95 & 0.13 & 0.04 \\
Public speaking anxiety & 0.72 & 0.57 & 0.34 & 0.20 \\
Emotionality & 0.89 & 0.8 & 0.14 & 0.09 \\
Self-control & 0.86 & 0.61 & 0.21 & 0.14 \\
Sociability & 0.91 & 0.77 & 0.17 & 0.11 \\
Well-being & 0.85 & 0.72 & 0.25 & 0.12 \\
Modified & & & & \\
Public speaking anxiety & 0.98 & 0.98 & 0.13 & 0.03 \\
Emotionality & 0.96 & 0.94 & 0.11 & 0.05 \\
Self-control & 0.98 & 0.95 & 0.13 & 0.05 \\
Sociability & 0.99 & 0.98 & 0.09 & 0.03 \\
Well-being & 0.98 & 0.98 & 0.07 & 0.04 \\
\hline
\end{tabular}

Note. GFI, goodness-of-fit-index; $\mathrm{CFI}$, comparative fit index; RMSEA, root mean square residual; SRMR, standardized root mean square residual.

Table 2. Descriptive statistics and internal consistency reliability

\begin{tabular}{|c|c|c|c|c|c|c|}
\hline Variable & Range & Mean & $S D$ & Skewness & Kurtosis & Cronbach's alpha \\
\hline Self-efficacy & $1.00-7.00$ & 5.38 & 1.00 & -.72 & .95 & .89 \\
\hline Writing apprehension & $1.00-7.00$ & 3.49 & 1.42 & .36 & -.24 & .89 \\
\hline Public speaking anxiety & $1.25-7.00$ & 4.05 & 1.27 & .05 & -.51 & .89 \\
\hline Emotionality & $2.00-7.00$ & 4.66 & 1.15 & .02 & -.69 & .73 \\
\hline Self-control & $1.50-7.00$ & 4.19 & 1.08 & .18 & -.23 & .64 \\
\hline Sociability & $1.75-7.00$ & 4.50 & 1.12 & .001 & -.73 & .66 \\
\hline Well-being & $2.40-7.00$ & 5.18 & 1.03 & -.21 & -.76 & .66 \\
\hline
\end{tabular}

Note. SD, standard deviation. 
Table 3. Homogeneity

\begin{tabular}{|c|c|c|c|c|c|c|c|c|}
\hline Subsample & $n$ & Emotionality & Self-control & Well-being & Sociability & Self-efficacy & $\begin{array}{c}\text { Public speaking } \\
\text { anxiety }\end{array}$ & $\begin{array}{c}\text { Writing } \\
\text { apprehension }\end{array}$ \\
\hline Accounting & 27 & 4.13 & 4.04 & 4.86 & 4.17 & 5.33 & 4.10 & 4.07 \\
\hline Business analytics & 8 & 4.67 & 4.06 & 5.23 & 4.97 & 5.39 & $4.97^{*}$ & 3.38 \\
\hline Business Ed & 25 & 5.03 & 4.49 & 5.30 & 4.69 & 5.47 & 4.08 & 3.85 \\
\hline Business IT/IS & 36 & 4.63 & 4.46 & 5.32 & 4.61 & 5.43 & $3.49 *$ & 3.12 \\
\hline Economics & 26 & 4.72 & 4.13 & 5.24 & 4.39 & 5.47 & 4.56 & 3.59 \\
\hline Finance & 6 & 4.69 & 3.89 & 5.67 & 4.96 & 5.98 & 4.46 & 4.19 \\
\hline Management & 51 & 4.78 & 4.30 & 5.25 & 4.51 & 5.04 & 3.83 & 3.32 \\
\hline Marketing & 23 & 4.56 & 4.03 & 5.03 & 4.37 & 5.64 & 4.30 & 3.03 \\
\hline Supply chain & 22 & 4.71 & 3.76 & 5.04 & 4.48 & 5.49 & 4.08 & 3.63 \\
\hline Males & 90 & 4.62 & 4.34 & 5.15 & 4.46 & 5.51 & 3.75 & 3.44 \\
\hline Females & 134 & 4.69 & 4.10 & 5.21 & 4.53 & 5.29 & 4.25 & 3.53 \\
\hline Freshmen & 34 & 4.65 & 4.08 & 5.19 & 4.18 & 5.17 & 3.80 & 3.47 \\
\hline Sophomores & 40 & 4.68 & 4.07 & 5.05 & 4.45 & 5.52 & 3.98 & 3.81 \\
\hline Juniors & 68 & 4.56 & 4.21 & 5.02 & 4.47 & 5.44 & 4.04 & 3.38 \\
\hline Seniors & 60 & 4.88 & 4.39 & 5.48 & 4.65 & 5.39 & 4.21 & 3.40 \\
\hline Graduate & 22 & 4.39 & 4.03 & 5.11 & 4.18 & 5.25 & 4.14 & 3.94 \\
\hline
\end{tabular}

Note. ${ }^{*} p<.05$.

of the variables: emotionality $(t(222)=-.44, p=.06)$, self-control $(t(222)=1.64, p=.53)$, well-being $(t(222)=-.37, p=.36)$, sociability $(t(222)=-.43, p=.61)$, self-efficacy $(t(222)=1.60, p$ $=.72)$, writing apprehension $(t(222)=-.51, p=.82)$, and public speaking anxiety $(t(222)=-2.92, p=.47)$. One-way ANOVAs revealed no statistically significant differences by rank: emotionality $(F(4,219)=0.99, p=.41)$, self-control $(F(4,219)=0.84$, $p=.50)$, well-being $(F(4,219)=1.87, p=.12)$, sociability $(F(4$, $219)=.79, p=.53)$, self-efficacy $(F(4,219)=0.74, p=.57)$, writing apprehension $(F(4,219)=0.81, p=.52)$ and public speaking $\operatorname{anxiety}(F(4,219)=.63, p=.64)$. As such, the overview revealed no substantive concerns for heterogeneity among the sample.

\section{Hypothesis Testing}

Hypotheses 1, 2, 3, and 4 predicted positive relationships between self-efficacy and each of the subdimensions of EQ. The data indicated positive relationships between self-efficacy and well-being (Hypothesis 3) and self-control (Hypothesis 4). However, Hypothesis 1 predicting a positive relationship between self-efficacy and emotionality was not supported. Hypothesis 2 predicting a positive relationship between self-efficacy and sociability was also unsupported. The correlation matrix can be found in Table 4.

Hypotheses 5 and 6 predicted negative relationships between self-efficacy and the communication anxieties of writing apprehension and public speaking anxiety. Hypothesis 6, predicting a negative relationship between self-efficacy and public speaking was supported. However, Hypothesis 5, predicting a negative
Table 4. Correlation matrix

\begin{tabular}{lcccccc}
\hline Variable & $\mathbf{1}$ & $\mathbf{2}$ & $\mathbf{3}$ & $\mathbf{4}$ & $\mathbf{5}$ & 6 \\
\hline Self-efficacy & & & & & & \\
Writing apprehension & .03 & & & & & \\
Public speaking anxiety & $-.18^{*}$ & .01 & & & & \\
Emotionality & .04 & $-.41^{*}$ & .07 & & & \\
Self-control & $.15^{*}$ & $-.41^{*}$ & $-.16^{*}$ & $.57^{*}$ & & \\
Sociability & .05 & $-.29^{*}$ & .04 & $.61^{*}$ & $.47^{*}$ & \\
Well-being & $.35^{*}$ & $-.20^{*}$ & $-.12^{*}$ & $.49^{*}$ & $.36^{*}$ & $.41^{*}$ \\
\hline
\end{tabular}

Note. ${ }^{*} p<.05$.

relationship between self-efficacy and writing apprehension was inconsistent with the data.

\section{Model Testing}

Before testing, it was anticipated that the hypothesized model depicted in Figure 1 would fail given that three of the hypotheses composing it are unsupported. The model was tested through structural equation modeling using the AMOS maximum likelihood parameter estimation algorithm. The hypothesized model had poor fit: GFI $=.92, \mathrm{CFI}=.83$, RMSEA $=.18$, and SRMR $=.13$. The observed model is shown in Figure 2 . Unsurprisingly, the model has poor fit.

The model was respecified removing the paths represented by unsupported hypotheses (Figure 3). The respecified model yielded good fit: GFI $=.99, \mathrm{CFI}=.97$, RMSEA $=.07$, and SRMR $=.04$. Therefore, the data support the respecified model. 


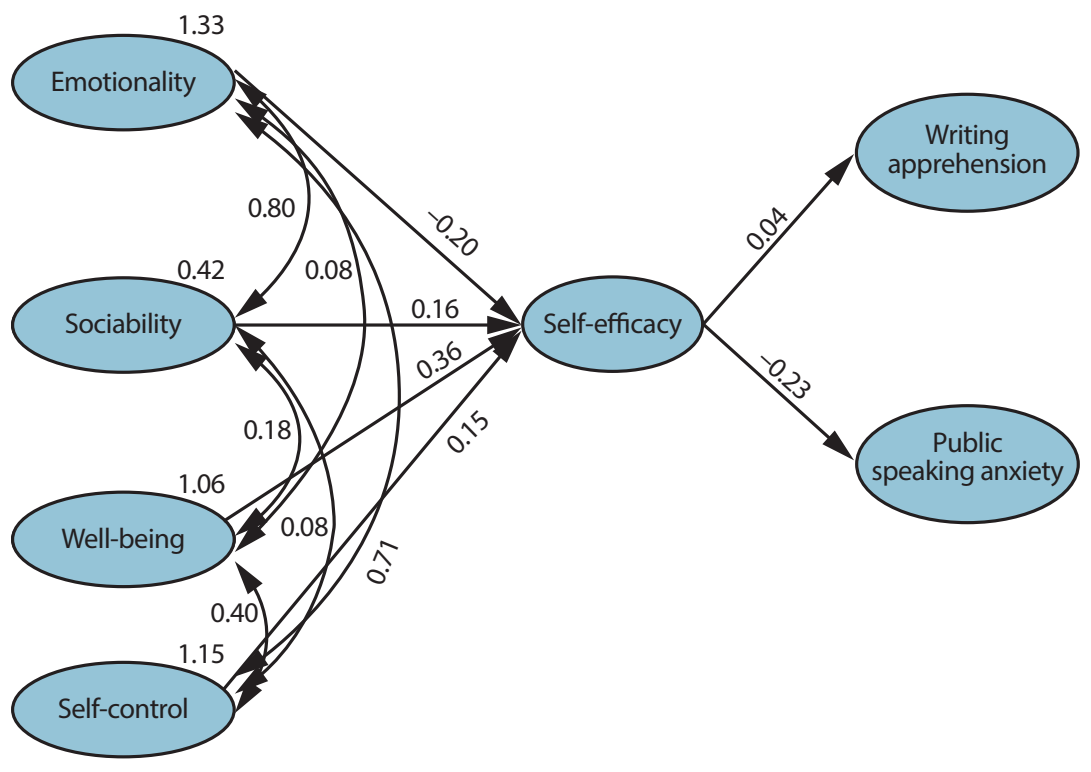

Figure 2. Observed model.

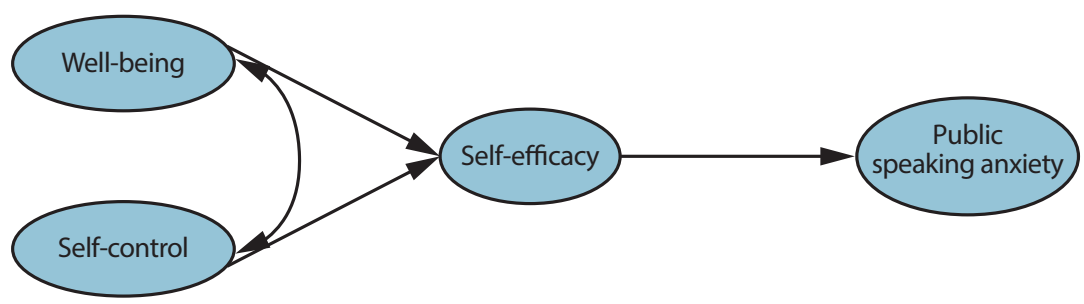

Figure 3. Supported model.

\section{Discussion}

The results of this study, while not as expected, have interesting implications for research and teaching. To begin, the predicted negative relationship between self-efficacy and writing apprehension was not observed. This is surprising, not just given the predictions of the IBM, but given that previous research has already observed the expected correlation (i.e., Autman \& Kelly, 2017). Perhaps this relationship was not observed in the current dataset because students enrolled in a variety of business courses, not specifically business communication as in the Autman and Kelly (2017) study, were solicited. Honicke and Broadbent (2016) found that the relationship between self-efficacy and academic performance is moderated by effort regulation and goal orientations. Therefore, perhaps the relationship between self-efficacy and writing anxiety was not found because these participants represented a variety of business majors who were not required to be currently enrolled in a writing intensive course and may not see writing as a critical part of their current or future success. If so, this means business faculty may need to do a better job of helping students understand that writing well will be an enduring demand of their anticipated career.

Although the relationship between writing apprehension and public speaking anxiety were not explicitly hypothesized in this study, spurious correlations were predicted through the hypothesized model. It is noteworthy that the data revealed no relationship between these communication anxieties. It is possible that written communication is simply not perceived to be face-threatening like public speaking anxiety. Because written communication is typically evaluated in a mediated way, such that communicators do not see immediate nonverbal judgment of their compositions, that it is potentially not as face-threatening and therefore anxiety inducing. Else, it could be that in this social media rich world in which texting, Tweeting, and Snapping have become norms of writing, the idea that having more focused written communication skills may not be held by the modern college student who actively engages in and is gratified by social media (Rathnayake \& Winter, 2018).

Another unexpected finding was that not all of the dimensions of EQ correlated with self-efficacy. Only well-being and 
self-control yielded statistically significant correlations with self-efficacy. So, while as expected, well-being and self-control both trend in positive ways with self-efficacy, sociability and emotionality did not. This gives a much more nuanced look at the previously established relationship between EQ and self-efficacy (e.g., Hen \& Goroshit, 2014; Salami, 2010) which used global measures of EQ. These results indicate that one's ability to perceive others' emotions (emotionality) and effectively respond to those emotions (sociability) are not related to their beliefs in their own abilities (self-efficacy). As such, it seems that students' EQ dimensions which give them advantages in connecting with others do not affect how competent they feel they are. This leads to a number of questions. Do business students not perceive that being able to affect the emotions of others is an important skill for their preparation as young professionals? For example, do they not perceive that the skill with which they communicate will affect the emotions of others during conflict in the workplace? Else, do they not believe that identifying and effectively responding to the emotions of others is a skill rather than an act of chance? Future research should strive to understand the disconnect between self-efficacy and EQ related to communicating with others.

Consistent with expectations though, one's ability to regulate their emotions towards happiness (well-being) and ability to manage stress (self-control) are positively related to self-efficacy. Also, as anticipated, self-efficacy was negatively related to public speaking anxiety. The data were further consistent with a path model in which well-being and self-control indirectly influence public speaking anxiety through the mediation of self-efficacy. In short, the better students perceive themselves to be at controlling their own feelings, the more confident they feel in their abilities and therefore the less anxiety they feel when giving or anticipating that they will give a presentation.

\section{Implications for Educators}

Individuals who suffer from public speaking anxiety struggle to give strong presentations (McCroskey, 1982; Prentis \& Violanti, 2019). When educators or supervisors see consistently weak presentation skills from someone who otherwise reliably produces strong work, public speaking anxiety is likely the reason for this poor presentation performance. By assisting these individuals in overcoming their public speaking anxiety, they will be able to produce presentations that are both more engaging for audience members and effective in information delivery.

The value of path modeling is that it helps scholars find the variables at the beginning of chains of influence. These exogenous variables, the first variables in the chains must be addressed to ultimately influence the variables at the end of the chain.
Therefore, though self-efficacy is the direct influence of students' public speaking anxiety, the results of this study indicate that to help students with their public speaking anxiety, educators must address EQ. However, these interventions cannot focus on improving their perception of others' emotions or global EQ metrics (e.g., Ashkanasy \& Dasborough, 2003; Kelly \& Claus, 2015). Rather, the indirect influences of public speaking anxiety were well-being and self-control, which deal with students' ability to control their own emotions. Thus, educators who wish to help students with their public speaking anxiety must target these specific dimensions of EQ. As such, business communication professors (or workplace trainers) may benefit their students through engaging in activities to develop EQ (Cicilia et al., 2017; Kelly \& Claus, 2015; Mabry, 2011; Myers \& Tucker, 2005).

The results for this study also indicate the business majors may not understand the critical role of writing well outside of the business communication classroom. It may be that students have enough confidence in their microblog style of writing that they feel those skills transfer to all forms of writing. Therefore, it is the role of business professors, particularly those in business communication, to emphasize the need to hone writing skills to be successful at work, especially those skills required to write longer documents with well-crafted arguments and transitions that cannot take place in a microblog format.

Further, though more research is needed to confirm this, the results of this study indicate that students may perceive that they are not able, through their own skills, to recognize and influence the emotions of others. As students are trained to be managers that sometimes must have difficult conversations with subordinates, employees who may have to engage in articulated dissent, and coworkers who may have to engage in workplace conflict, business educators must impress on students that the skillfulness in which they communicate can affect the magnitude of the emotional reaction others will have to their communication. Student should also understand that by paying careful attention to the nonverbal cues of others give during communication, they can recognize their emotions. Being mindful of the current and anticipated feelings of other is a learnable, critical communication skill for future professionals. Infusing the business communication curriculum with presentations that include interactivity may help students refine their emotionality and sociability and help them recognize the importance of these skills.

\section{Limitations}

This study was limited in that it failed to collect data on whether students were currently enrolled in a business communication course. As such, it is unable to confirm its suspicions as to why the correlation between self-efficacy and writing apprehension 
was different than the Autman and Kelly (2017) findings.

Further, the study was limited by some measurement noise. Consistent with past research on EQ among business students (e.g., Fall et al., 2013), the EQ submeasures yielded low reliability scores. The RMSEA was also slightly elevated for the public speaking anxiety, emotionality, and self-control measures. Therefore, the authors echo the call of Croucher et al. (2019) and Kelly and Westerman (2020) to continue the pursuit of measurement refinement in communication research.

Finally, this study was limited by its use of cross-sectional data. The purpose of this study was to attempt to identify exogenous variables that influence communication anxieties. However, with cross-sectional data it is only possible to conclude that the data fit a pattern consistent with causation rather than truly demonstrate causation.

\section{Conclusion}

This study gives insight into writing apprehension and public speaking anxiety. The data indicate that by training speakers to have better emotional control, business educators and likely workplace trainers can have an impact on their public speaking anxiety so that these individuals can be more effective presenters. The results also showed that while there were moderate correlations between writing apprehension and the dimensions of EQ, that they do not appear to fit a path model with the mediation of self-efficacy as predicted by the IBM. Future research should continue to explore additional writer characteristics that may be bolstered to reduce their writing apprehension.

\section{References}

Abdollahi, A., \& Abu Talib, M. (2016). Self-esteem, body-esteem, emotional intelligence, and social anxiety in a college sample: The moderating role of weight. Psychology, Health \& Medicine, 21(2), 221-225.

Ahrens, C. A., Meyers, C., Irlbeck, E., Burris, S., \& Roach, D. (2016). Exploring agricultural communications students' perceptions of communication apprehension and writing apprehension in the classroom. Journal of Agricultural Education, 57(2), 119-133.

Artino, A. R. (2012). Academic self-efficacy: From educational theory to instructional practice. Perspectives on Medical Education, 1(2), 76-85.

Ashkanasy, N. M., \& Dasborough, M. T. (2003). Emotional awareness and emotional intelligence in leadership teaching. Journal of Education for Business, 79(1), 18-22.

Autman, H., \& Kelly, S. (2017). Reexaming the writing apprehension measure. Business and Professional Communication Quarter- ly, 80(4), 516-529.

Bandura, A. (1986). Social foundations of thought and action: A social cognitive theory. Englewood Cliffs, NJ: Prentice-Hall.

Bar-On, R. (2006). The bar-on model of emotional-social intelligence (ESI). Psicothema, 18(Suppl. 1), 13-25.

Bodie, G. D. (2010). A racing heart, rattling knees, and ruminative thoughts: Defining, explaining, and treating public speaking anxiety. Communication Education, 59(1), 70-105.

Cassidy, S. (2015). Resilience building in students: The role of academic self-efficacy. Frontiers in Psychology, 6(1781), 1-14.

Cicilia, V., Musa, D., Walanda, D. K., Tangge, L., \& Jamhari, M. (2017). Use of Google apps education to improve teachers competence through lecturer community service. Advances in Social Science, Education, and Humanities Research, 174, 518-522.

Colfax, R. S., Rivera, J. J., \& Perez, K. T. (2010). Applying emotional intelligence (EQ-I) in the workplace: Vital to global business success. Journal of International Business Research, 9, 89-98.

Croucher, S. M., Kelly, S., Rahmani, D., Jackson, K., Galy-Badenas, F., Lando, A. L., ... Orunbekov, B. (2019). A multi-national validity analysis of the Personal Report of Communication Apprehension (PRCA-24). Annals of the International Communication Association, 43(3), 193-209.

Daly, J. A., \& Miller, M. D. (1975). The empirical development of an instrument to measure writing apprehension. Research in the Teaching of English, 9(3), 242-249.

Dwyer, K. K., \& Davidson, M. M. (2012). Is public speaking really more feared than death? Communication Research Reports, 29(2), 99-107.

Fall, L. T., Kelly, S., Macdonald, P., Primm, C., \& Holmes, W. (2013). Intercultural communication apprehension and emotional intelligence: Preparing business students for career success. Business and Communication Quarterly, 76(4), 412-426.

Finn, A. N., Sawyer, C. R., \& Behnke, R. R. (2009). A model of anxious arousal for public speaking. Communication Education, 58(3), 417-432.

Fischer, L. M., Meyers, C. A., \& Dobelbower, S. E. (2017). Exploring how pedagogical strategies change student perceptions of writing apprehension. Journal of Agricultural Education, 58(4), 254-268.

Gaffney, A. L. H. (2013). Communication instruction in landscape architecture courses: A model and effects on students' self-efficacy. Journal of Business and Technical Communication, 28(2), 158-186.

Harris, S. R., Kemmerling, R. L., \& North, M. M. (2002). Brief virtual reality therapy for public speaking anxiety. Cyberpsychology \& Behavior, 5(6), 543-550.

Hen, M., \& Goroshit, M. (2014). Academic procrastination, emotional intelligence, academic self-efficacy, and GPA: A comparison between students with and without learning disabilities. Journal of Learning Disabilities, 47(2), 116-124. 
Homer, S. R., Deeprose, C., \& Andrade, J. (2016). Negative mental imagery in public speaking anxiety: Forming cognitive resistance by taxing visuospatial working memory. Journal of Behavior Therapy and Experimental Psychiatry, 50, 77-82.

Honicke, T., \& Broadbent, J. (2016). The influence of academic self-efficacy on academic performance: A systematic review. Educational Research Review, 17, 63-84.

Johnson, L. L., \& Kelly, S. (2020). Student predispositions as predictors of dissent behaviors in supply chain courses. Decision Sciences Journal of Innovative Education, 18(2), 270-290.

Jordan, P. J., \& Troth, A. (2011). Emotional intelligence and leader member exchange: The relationship with employee turnover intentions and job satisfaction. Leadership and Organization Development Journal, 32(3), 260-280.

Kelly, S., \& Claus, C. J. (2015). Practicing nonverbal awareness in the asynchronous online classroom. Communication Teacher, 29(1), 37-41.

Kelly, S., \& Gaytan, J. (2020). The effect of instructors' immediate behaviors and clarity on student writing apprehension. Business and Professional Communication Quarterly, 83(1), 96-109.

Kelly, S., Rice, C., Wyatt, B., Ducking, J., \& Denton, Z. (2015). Teacher immediacy and decreased student quantitative reasoning anxiety: The mediating effect of perception. Communication Education, 64(2), 171-186.

Kelly, S., Romero, A., Morrow, J. A., Denton, Z., \& Ducking, J. (2020). Instructor misbehaviors and math anxiety. Communication Reports, 33(1), 27-40.

LaBelle, S., Martin, M. M., \& Weber, K. (2013). Instructional dissent in the college classroom: Using the instructional beliefs model as a framework. Communication Education, 62(2), 169-190.

Limpo, T. (2018). Development of a short measure of writing apprehension: Validity evidence and association with writing frequency, process, and performance. Learning and Instruction, 58, 115-125.

Lindner, P., Miloff, A., Fagernäs, S., Andersen, J., Sigeman, M., Andersson, G., ... Carlbring, P. (2019). Therapist-led and self-led one-session virtual reality exposure therapy for public speaking anxiety with consumer hardware and software: A randomized controlled trial. Journal of Anxiety Disorders, 61, 45-54.

Linnenbrink, E. A., \& Pintrich, P. R. (2003). The role of self-efficacy beliefs in student engagement and learning in the classroom. Reading \& Writing Quarterly, 19(2), 119-137.

Lucchetti, A. E., Phipps, G. L., \& Behnke, R. R. (2003). Trait anticipatory public speaking anxiety as a function of self-efficacy expectations and self-handicapping strategies. Communication Research Reports, 20(4), 348-356.

Mabry, S. (2011). The performing life: A singer's guide to survival. Lanham, MD: Scarecrow Press.
Mascle, D. D. (2013). Writing self-efficacy and written communication skills. Business Communication Quarterly, 76(2), 216-225.

Matthew, M., \& Gupta, K. S. (2015). Transformational leadership: Emotional intelligence. SCMS Journal of Indian Management, 12(2), 75-89.

McCroskey, J. C. (1982). Oral communication apprehension: A reconceptualization. In M. Burgoon (Ed.), Communication yearbook 6 (pp. 136-170). Beverly Hills, CA: Sage.

Miller, H., \& Bichsel, J. (2004). Anxiety, working memory, gender, and math performance. Personality and Individual Differences, 37, 591-606.

Moon, T. W., \& Hur, W. M. (2011). Emotional intelligence, emotional exhaustion, and job performance. Social Behavior and Personality, 39(8), 1087-1096.

Myers, L. L., \& Tucker, M. L. (2005). Increasing awareness of emotional intelligence in a business curriculum. Business Communication Quarterly, 68(1), 44-51.

Petrides, K. V., \& Furnham, A. (2006). The role of trait emotional intelligence in a gender-specific model of organizational variables. Journal of Applied Social Psychology, 36(2), 552-569.

Petrides, K. V., Mikolajczak, M., Mavroveli, S., Sanchez-Ruiz, M. J., Furnham, A., \& Pérez-González, J. C. (2016). Developments in trait emotional intelligence research. Emotion Review, 8(4), 335-341.

Prentiss, S., \& Violanti, M. T. (2019). Communication apprehension and anxiety in the CMC workplace. In S. Kelly (Ed.), Computer-mediated communication for business: Theory to practice (pp. 43-54). Newcastle upon Tyne, UK: Cambridge Scholars.

Rathnayake, C., \& Winter, J. S. (2018). Carrying forward the uses and grats 2.0 agenda: An affordance-driven measure of social media uses and gratifications. Journal of Broadcasting \& Electronic Media, 62(3), 371-389.

Salami, S. O. (2010). Emotional intelligence, self-efficacy, psychological well-being and students' Attitudes: Implications for quality education. European Journal of Educational Studies, 2(3), 247-257.

Schunk, D. H. (2003). Self-efficacy for reading and writing: Influence of modeling, goal setting, and self-evaluation. Reading \& Writing Quarterly, 19(2), 159-172.

Schwarzer, R., \& Jerusalem, M. (1995). Generalized self-efficacy scale. In J. Weinman, S. Wright, \& M. Johnston (Eds.), Measures in health psychology: A user's portfolio: Causal and control beliefs (pp. 35-37). Windsor, CT: NFER-Nelson.

Serrat, O. (2017). Knowledge solutions: Tools, methods, and approaches to drive organizational performance. New York, NY: Springer.

Weber, K., Martin, M. M., \& Myers, S. A. (2011). The development and testing of the instructional beliefs model. Communication Education, 60(1), 51-74.

Zimmerman, B. J. (2000). Self-efficacy: An essential motive to learn. Contemporary Educational Psychology, 25(1), 82-91. 